\title{
Quantitative trait loci determining autogeny and body size in the Asian tiger mosquito (Aedes albopictus)
}

\author{
A Mori ${ }^{1}, \mathrm{~J}$ Romero-Severson ${ }^{1}$, WC Black $\mathrm{IV}^{2}$ and DW Severson ${ }^{1}$ \\ ${ }^{1}$ Department of Biological Sciences, Center for Global Health and Infectious Diseases, University of Notre Dame, Notre Dame, IN, USA \\ and ${ }^{2}$ Department of Microbiology, Immunology and Pathology, Colorado State University, Fort Collins, CO, USA
}

\begin{abstract}
The majority of mosquito species require a blood meal to stimulate vitellogenesis and subsequent oviposition (anautogeny), but some autogenous individuals complete their first ovarian cycle without a blood meal. Autogeny may be facultative or obligatory. In this study, we selected for an autogenous strain in the Asian tiger mosquito Aedes albopictus and examined an $F_{1}$ intercross population for quantitative trait loci (QTL) determining the autogeny trait as well as wing length as a proxy for body size. Using composite interval mapping, we identified four QTL for each trait and observed considerable overlap in genome positions between each QTL for autogeny (follicle size) and wing length. Most QTL were minor in magnitude, individually explaining $<10 \%$ of the phenotypic variation. Alleles from the autogenous parent generally showed a dominance or overdominance effect on both phenotypes. Strong genetic and phenotypic
\end{abstract}

correlations indicate that autogeny and wing length are determined by up to four clusters of tightly linked genes or the potential pleiotropic effects of single genes. Although females from the autogenous strain produced approximately fivefold more eggs following a blood meal than through autogeny, we suggest that the maintenance of alleles for autogeny in natural populations is likely due to balancing selection. Autogeny should be favored under conditions of limited host availability for blood feeding or increased defensive behavior by the host and adequate larval nutrition. Correlation between autogeny and body size may reflect an increased ability for larger females to accumulate sufficient nutrient reserves to support oogenesis without the requirement for a blood meal.

Heredity (2008) 101, 75-82; doi:10.1038/hdy.2008.32; published online 7 May 2008

Keywords: anautogeny; follicle; linkage; overdominance; oviposition; QTL

\section{Introduction}

Blood feeding to obtain a protein source for vitellogenesis has evolved independently many times among the Arthropoda, including within nine dipteran insect families (Black and Kondratieff, 2005). The majority of mosquito species (family Culicidae) are anautogenous or require a blood meal to stimulate vitellogenesis and subsequent oviposition (Foster, 1995; Attardo et al., 2005). However, autogenous females are able to complete their first ovarian cycle without a blood meal, and this trait may be facultative or obligatory, depending on the species. Autogeny was first identified in Culex pipiens and has been reported to occur at low frequencies among many mosquito species, mainly among culicines but including a few Anopheles spp. (Clements, 1963, 1992; Spielman, 1971). Depending on the species, expression of the trait is dependent on larval and adult nutrition as well as female mating status. In general, autogeny is enhanced among individuals provided good larval

Correspondence: Dr DW Severson, Department of Biological Sciences, Center for Global Health and Infectious Diseases, University of Notre Dame, 137 Galvin Life Sciences, Notre Dame, IN 46556-5645, USA.

E-mail: severson.1@nd.edu

Received 4 December 2007; revised and accepted 26 March 2008; published online 7 May 2008 nutrition, a carbohydrate source upon adult eclosion and the opportunity to mate.

The Asian tiger mosquito, Aedes albopictus, while native to Asia, is expanding its range through human activities and now occupies much of southeast Asia, most Pacific and Indian Ocean islands, parts of Australasia, Africa and Europe and both North and South America (Hawley, 1988; Gubler, 2003; Medlock et al. 2006). Ae. albopictus is generally found in suburban and rural areas, and is a competent vector for dengue viruses (DENV) and other arboviruses (Gubler and Rosen, 1976; Mitchell, 1991). Recently, Ae. albopictus was confirmed as responsible for an epidemic of chikungunya virus on Reunion island in the Indian Ocean (Reiter et al., 2006). Ae. albopictus also has potential as a maintenance vector for DENV as laboratory strains showed high vertical transmission rates of DENV-1, wherein infected females transmitted virus directly to some of their offspring (Bosio et al., 1992).

Ae. albopictus populations have been reported to exhibit low levels of autogeny (Bat-Miriam and Craig, 1966; Mori, 1979; Cui, 1982; Sprenger and Wuithiranyagool, 1986; Chambers and Klowden, 1994). The autogeny index (number of eggs oviposited divided by the total number of females) varied from $\sim 0.3$ to 3.0 among natural populations (Bat-Miriam and Craig, 1966; Cui, 1982; Chambers and Klowden, 1994). Newly emerged 
autogenous females, while the similar mass as anautogenous females, contained greater amounts of protein and lipid reserves available for metabolic breakdown (Chambers and Klowden, 1994). Ovary development is limited among autogenous individuals starved as adults, and is only initiated following at least minimal access to a carbohydrate food source or even through abdominal distention by a saline enema, suggesting involvement of gut stretch receptors (Chambers and Klowden, 1996).

The genetic basis for autogeny has been examined in several mosquito species. With Culex pipiens, studies indicated a complex or multigenic mode of inheritance for autogeny. Spielman (1957) suggested that the expression was controlled by genes located on each of the three chromosomes, although the results also suggested that one of the autosomes carrying the gene for yellow fat color may not be involved. The specific gene dosage within individuals was postulated to impact penetrance and expressivity of autogeny. Another study (Aslamkhan and Laven, 1970) implicated primary involvement of two genes located on chromosomes one and three, respectively; they suggested that the gene on chromosome one had a dominant effect on autogeny, while the gene on chromosome three had at least three alleles with variable effects on the phenotype that depended upon the specific allele combination. Multigenic control of autogeny has also been implicated for Ae. atropalpus (O'Meara, 1972), Ae. scutellaris (Hoyer and Rozeboom, 1976; Trpis, 1978) and Ae. togoi (Thomas and Leng, 1972).

In this study, we selected for a highly autogenous strain of Ae. albopictus and performed quantitative trait locus (QTL) mapping in a population segregating for autogeny as evidenced by ovarian follicle size. In addition, as our autogenous strain was significantly larger than our anautogenous strain, we also identified QTL for wing length as a proxy for body size. This allowed us to compare genome positions of QTL for autogeny with those for body size and thereby investigate the potential for genetic interaction between traits.

\section{Materials and methods}

\section{Mosquito strains and rearing methods}

Our anautogenous Ae. albopictus strain (Sri Lanka; SL) was established from stocks collected in SL. We selected our autogenous strain (autogenous strain selected from Tok; Tok-au) from a strain (Tokushima; Tok) established from stocks collected in Tok, Japan. Both the SL and Tok strains have been maintained in the laboratory for an unknown number of generations.

Mosquitoes were maintained in an environmental chamber held at $26^{\circ} \mathrm{C}, 85 \%$ relative humidity, with $16-\mathrm{h}$ light/8-h dark cycles that included a $1 \mathrm{~h}$ crepuscular period at the beginning and end of each cycle. Larvae were reared on a dried bovine liver powder suspension. Adults were provided a $2 \%$ sugar solution ad libitum. For colony maintenance, SL and Tok strain adult females were blood-fed on anaesthetized rats approximately 1 week following eclosion, while our Tok-au strain was maintained without blood feeding. Our protocol for the maintenance and care of experimental animals was reviewed and approved by the Institutional Animal Care and Use Committee at the University of Notre Dame.
Genetic and phenotypic data were obtained from an $F_{1}$ intercross mapping population. The population was prepared by pairwise matings, wherein a single SL strain male and five Tok-au strain females $\left(\mathrm{F}_{18}\right.$ generation) were placed in a $450 \mathrm{ml}$ mesh-covered carton within several hours of eclosion. After 3 days, individual females were transferred to $10 \mathrm{ml}$ glass vials and provided a strip of paper towel as an oviposition substrate. $F_{1}$ progeny from autogenous females were subsequently reared and pairwise mated as described above, with the exception that following autogenous oviposition, the $F_{1}$ females were then blood fed on anaesthetized rats to increase the number of $\mathrm{F}_{2}$ individuals available for mapping efforts. $\mathrm{F}_{2}$ adult females were allowed to mature for 5 days and then were frozen and stored at $-80{ }^{\circ} \mathrm{C}$.

\section{Phenotype analysis}

Ovarian follicle size was used as a proxy for the autogeny phenotype as follicle development is only observed among non-blood fed females carrying the autogeny trait. For our $\mathrm{F}_{2}$ segregating population, adult female ovaries at 5 days posteclosion were dissected in distilled water and the autogeny phenotype scored as the mean of the three most developed ovarian follicles as measured along their longitudinal axis using a dissecting microscope with an optical micrometer. We also removed one wing and measured wing length as the distance from the apical notch to the tip of the wing, but excluding the fringe scales, because wing length has been shown to be a reliable proxy for body size in mosquitoes (Van Handel and Day, 1989).

Progeny representing the individual strains were evaluated for phenotypes including wing length among males and females, number of eggs produced per female (fecundity) and eggs produced per female that subsequently produced first instar larvae (fertility).

Statistical analyses of phenotypic data were performed using $\mathrm{R}$ version 2.6.0. Analysis of variance (ANOVA) was used to investigate effects of strain on individual phenotypes. Data for egg hatch rate were arcsine square root transformed before analysis. The Tukey honestly significant difference (HSD) test was used to identify significant differences among strains. The Pearson correlation coefficient was determined for wing length and follicle size among our $\mathrm{F}_{2}$ segregating population.

\section{DNA extraction and genotyping}

Following dissections for phenotypic analyses, DNA extractions from individual female carcasses were performed as described previously (Severson, 1997). DNA from each mosquito was resuspended in $15 \mu \mathrm{l}$ of TE (10 mM Tris-Hcl, 1 mM EDTA, pH 8.0).

For restriction fragment length polymorphism marker analysis, $13 \mu \mathrm{l}$ of DNA preparation from each female was digested with EcoRI, Southern blotted and hybridized with ${ }^{32}$ P-labelled probe DNA as described elsewhere (Severson, 1997). High stringency hybridizations were performed at $65^{\circ} \mathrm{C}$ and membranes were washed for $15 \mathrm{~min}$ each at room temperature and at $65^{\circ} \mathrm{C}$ in $2 \times \mathrm{SSC} / 0.1 \%$ SDS followed by $15 \mathrm{~min}$ at $65^{\circ} \mathrm{C}$ in $0.2 \times$ SSC $/ 0.1 \%$ SDS. All of these markers were Aedes aegypti cDNA clones mapped as restriction fragment length polymorphism loci (Severson et al., 2002), including several that were previously used to construct a 
comparative linkage map for Ae. albopictus (Severson et al., 1995).

PCR amplifications for comparative anchor-tagged sequences and expressed sequence tag (EST) marker analyses were performed as described previously (Chambers et al., 2003) using $1 \mu \mathrm{l}$ of a 1:1200 dilution of genomic DNA as template. Five microlitres of PCR products were mixed with $3 \mu \mathrm{l}$ of gel loading solution $(0.01 \mathrm{~N} \mathrm{NaOH}, 95 \%$ formaldehyde, $0.05 \%$ bromophenol blue and $0.05 \%$ xylene cyanol) and fractionated as singlestrand conformation polymorphisms on 5\% non-denaturing polyacrylamide gel marker analysis after Black and DuTeau (1997). Products were visualized by silver staining following Bassam et al. (1991).

Genotypes for all marker loci were assigned to $F_{2}$ progeny based on initial screening of the parental genotypes. We observed transmission ratio distortion (at $\alpha=0.01$ ) among the $F_{2}$ progeny for all marker loci on chromosome 1,12 of 16 loci on chromosome 2 and 4 of 13 loci on chromosome 3. Severe distortion was expected for chromosome 1 due to autosomal sex determination in Ae. albopictus (Mutebi et al., 1997). Transmission distortion for chromosomes 2 and 3 was predominantly due to a deficit in Tok-au homozygotes; however, all expected genotypic classes were represented at each locus. While this may have influenced our power to detect QTL, we believe that it had limited impact on our results.

\section{QTL analysis}

Multipoint linkage analysis was performed using the MAPMAKER computer program (Lander et al., 1987) with an LOD of 3.0 as the threshold for significance. QTL controlling the autogeny and wing length traits were identified using the QTL Cartographer computer package (Basten et al., 2001). Markers with significant partial regression coefficients were identified with the SRmapqtl function by forward-backward stepwise regression. QTL affecting each trait were identified by composite interval mapping (CIM) (Zeng, 1993, 1994) using the Zmapqtl function with model 6 . The comparison-wise and experiment-wise likelihood ratio (LR) thresholds for identifying a QTL were determined by permutation test (Churchill and Doerge, 1994). The data were permuted 1000 times and critical LR values were determined for the $\alpha=0.1,0.05$ and 0.01 significance levels. An LR decline of $\geqslant 9.21$ (equals an LOD decline of $\geqslant 2.0$ ) between adjacent peaks on a linkage group was used to define linked QTL. The best estimate for QTL location was assumed to be the position having the largest LR value and one-LOD support limit were calculated around this value.

Zmapqtl also estimates additive (a) and dominance (d) effects of the detected QTL. Additive and dominance effects are calculated relative to alleles at the marker locus nearest the predicted QTL from the designated ' $A$ ' parent in the cross. For additive effects, the BB homozygote effect is set to zero and $A A$ effect $=2 \times A B$ effect. For dominance effects, the BB homozygote effect is set to zero and AA effect $=A B$ effect. Mode of gene action was determined as the absolute value of $d / a$ where additive $=0-0.20$, partial dominance $=0.21-0.80$, dominance $=0.81-1.20$ and overdominance $>1.20$ (Stuber et al., 1987; Babu et al., 2006).

\section{Results}

\section{Autogenous strain selection}

The Tok-au strain was selected following the serendipitous observation of pre-blood feeding oviposition in the Tok colony cage. Adults reared from these eggs (two females and five males) were sibmated and female offspring evaluated for the autogeny trait. Autogenous females were again sibmated and evaluated. By the $\mathrm{F}_{4}$ generation of selection for autogenous females and sibmating, the majority of females were autogenous, and thereafter were maintained as a self-sustaining colony (i.e., without blood feeding).

\section{Linkage analysis}

The linkage map was constructed with five restriction fragment length polymorphism, eight Ae. aegypti-derived comparative anchor-tagged sequences and $25 \mathrm{Ae}$. albopictus EST marker loci for 221 female progeny from a Tok-au $\times \mathrm{SL} \mathrm{F}_{1}$ intercross population. This encompassed nine markers on chromosome 1 covering $48.3 \mathrm{cM}$ (Kosambi units) for a mean interval size of $5.4 \mathrm{cM}, 16$ markers on chromosome 2 covering $99.4 \mathrm{cM}$ for a mean interval size of $6.2 \mathrm{cM}$ and 13 markers on chromosome 3 covering $68.1 \mathrm{cM}$ for a mean interval size of $5.2 \mathrm{cM}$ Details on individual markers, including PCR primer sequences, are given in Supplementary Table 1. As observed with previous broad-scale comparative mapping of Ae. aegypti and Ae. albopictus (Severson et al., 1995), the Ae. aegypti-derived markers used in this study (see Severson et al., 2002) showed complete linear order conservation in Ae. albopictus. As sex determination in Ae. albopictus is controlled by a single autosomal locus on chromosome 1 (Mutebi et al., 1997), few paternal homozygotes were obtained for chromosome 1 markers (see Severson et al., 1993).

\section{Phenotype analysis}

As male mosquitoes are smaller than females, we examined body size independently in each sex (Yan et al., 1997). We observed significant differences among females and males between strains (Figure 1a, ANOVA for females, $F_{1,148}=171.10 ; P<0.0001$ and Figure $1 \mathrm{~b}$, ANOVA for males, $\left.F_{1,148}=289.94 ; P<0.0001\right)$. With both females and males, the SL strain was significantly smaller than either the Tok or Tok-au strains, which did not differ significantly (Tukey HSD test; $P<0.05$ ).

We observed significant differences among strains in fecundity and fertility. Total number of eggs (fecundity) per female varied significantly (Figure 2a, ANOVA, $\left.F_{1,150}=94.10 ; P<0.0001\right)$ among strains. Females of each strain produced significantly more eggs following a blood meal (including the Tok-au strain) than the Tok-au strain produced autogenously, while the Tok and Tok-au strains produced similar numbers of eggs and each produced significantly more eggs than the SL strain following a blood meal (Tukey HSD test; $P<0.05$ ). For these studies, the Tok-au females were first allowed to produce an autogenous egg batch and were then provided a blood meal to produce an anautogenous egg batch. Egg hatch rate (fertility) among strains also varied significantly (Figure $2 b$, ANOVA, $F_{1,150}=19.33$; $P<0.0001)$, with eggs produced autogenously by the Tok-au strain reflecting a significantly decreased egg 

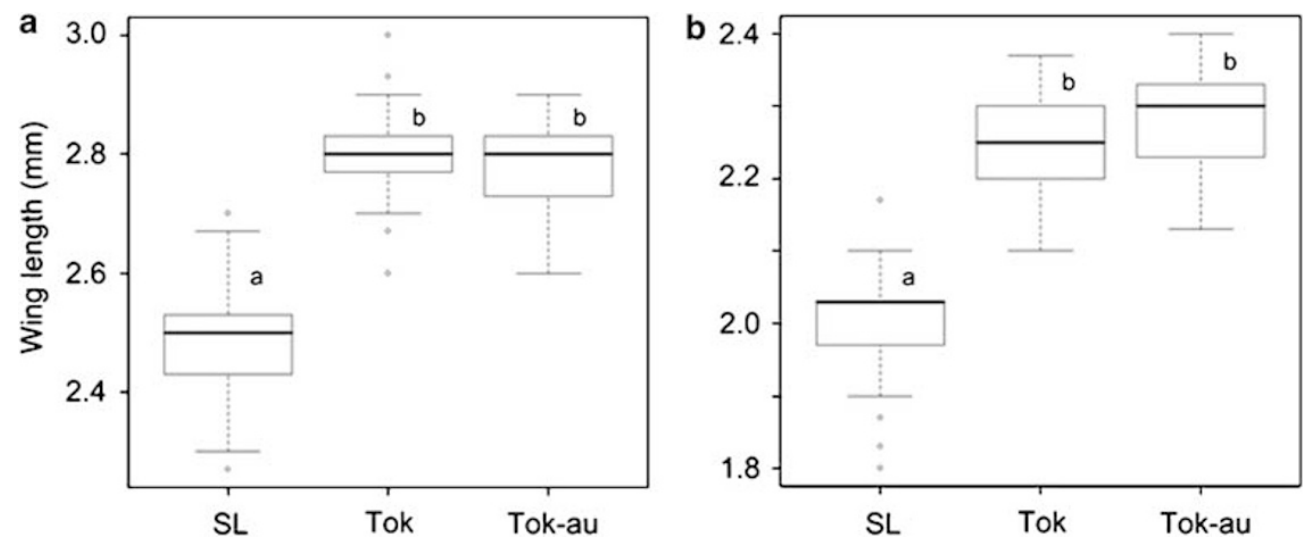

Figure 1 Variability in wing length among strains. (a) Females, (b) males. SL, Sri Lanka; Tok, Tokushima; Tok-au, autogenous strain selected from Tok. Box plots identify medians and quartiles, with whiskers representing the 10th and 90th percentiles. Open circles indicate outliers. Strains indicated by the same letter are not significantly different by the Tukey honestly significant difference (HSD) multiple comparisons of means test at $P=0.05$.
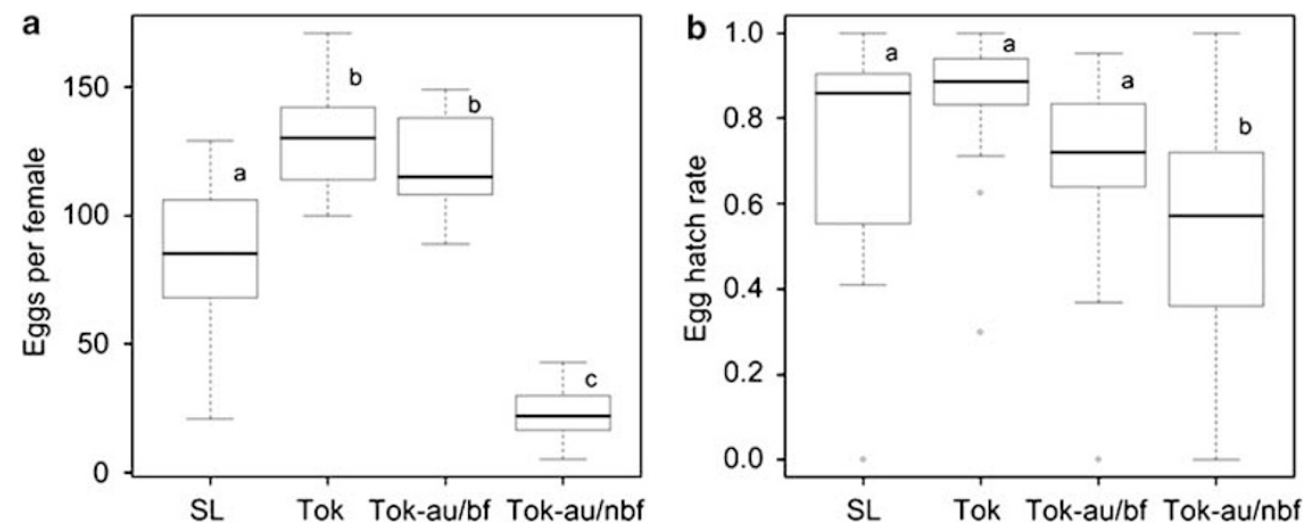

Figure 2 Comparisons of fecundity and fertility among strains. (a) Total eggs laid per female (fecundity). (b) Egg hatch rate per female (fertility). Symbols and conventions as in Figure 1.

hatch rate, while differences in egg hatch rate among eggs produced anautogenously by the three strains were not significant (Tukey HSD test; $P<0.05$ ).

\section{QTL analysis}

Composite interval mapping analysis of follicle size as a proxy for autogeny identified four QTLs: one on chromosome 1, two QTLs on chromosome 2 and one on chromosome 3 (Figure $3 \mathrm{a}$ and Table 1). QTLs on chromosomes 2 and 3 exceeded the $P=0.05$ or 0.01 experiment-wise threshold LR values, while the chromosome 1 QTL exceeded only the $P=0.1 \mathrm{LR}$ value and is therefore considered tentative. The phenotypic variation explained by individual QTL using CIM varied from $5.3-8.9 \%$, indicating that autogeny in Ae. albopictus is determined by the combined effects of multiple, minor effect ( $<10 \%$ individual contribution) genes (Table 1$)$. Using estimates of the additive (a) and dominance (d) effects of QTL as determined by Zmapqtl, we estimated the degree of dominance (d/a) for QTLs on chromosomes 2 and 3. QTL on chromosome 1 were not evaluated for $\mathrm{d} / \mathrm{a}$, because for most chromosome 1 loci, no paternal homozygotes were represented due to autosomal sex determination. The QTLs on chromosome 2, were most closely linked to AALUFO-84 and AALTM-69 loci, showed dominance and overdominance modes of gene action, respectively (Table 1 and Figures $4 a-d)$. The QTL on chromosome 3, most closely linked to the AALLV-66 locus, showed an additive effect. Gene effects were calculated relative to alleles from the Tok-au strain as the A parent in the cross. The observed effect of individual QTL was in the 'expected' direction, wherein larger follicle sizes were associated with the Tok-au alleles (Figures $4 a-d$ ).

CIM analysis of wing length identified four QTLs: one on chromosome 1, two on chromosome 2 and one on chromosome 3 (Figure $3 \mathrm{~b}$ and Table 1). Each QTL exceeded the $P=0.05$ or 0.01 experiment-wise threshold LR values obtained by permutation test. The phenotypic variation explained by individual QTL using CIM varied from 6.8 to $38.2 \%$, with three QTLs having a minor effect and one QTL with a major effect (Table 1 and Figures $4 \mathrm{e}-\mathrm{h}$ ). The QTLs on chromosome 2, most closely linked to the AALTM-430 and AALTM-69 loci, both exhibited overdominance. The QTL on chromosome 3, most closely linked to the AALLV-121 locus, showed a dominance effect. The observed effect of individual QTL was again in the expected direction, wherein larger wing size was associated with the Tok-au alleles (Figures $4 \mathrm{e}-\mathrm{h}$ ). 

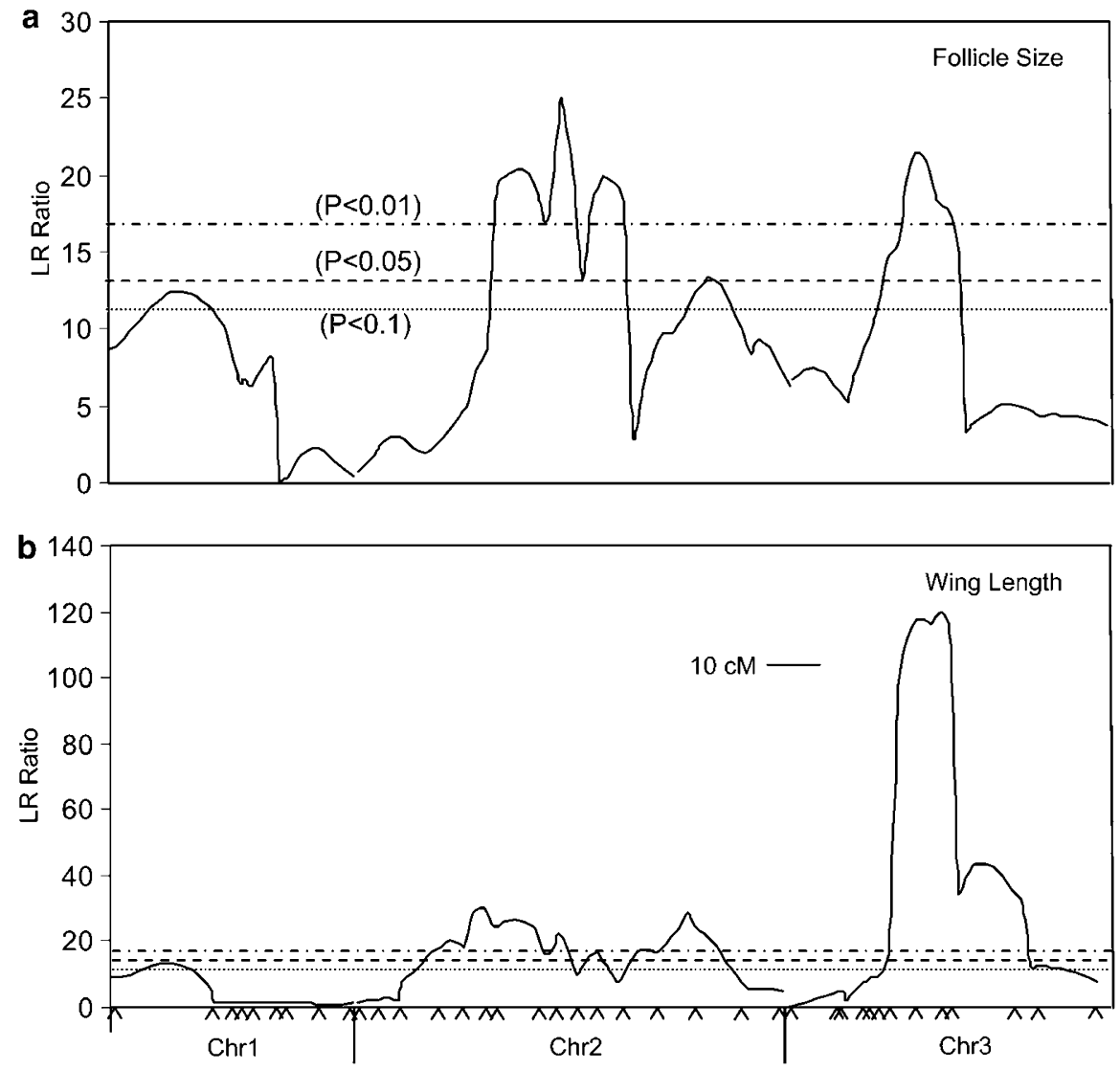

Figure 3 Likelihood ratio profiles identifying quantitative trait loci (QTL) for (a) follicle size and (b) wing length. Horizontal lines indicate the experiment-wise threshold values for identifying a QTL based on 1000 permutations. Relative positions of marker loci are indicated by ' $\wedge$ ' (see Supplementary Table 1).

Table 1 QTL identified for follicle size and wing length by composite interval mapping

\begin{tabular}{|c|c|c|c|c|c|c|c|c|c|c|}
\hline \multirow[t]{2}{*}{ Trait } & \multirow{2}{*}{$\begin{array}{c}\text { Chromo- } \\
\text { some }\end{array}$} & \multirow[t]{2}{*}{ Position $^{\mathrm{a}}$} & \multirow[t]{2}{*}{ Flanking markers } & \multirow{2}{*}{$\begin{array}{l}\text { Maximum } \\
\text { LR }\end{array}$} & \multirow{2}{*}{$\begin{array}{c}1-L O D \\
\text { interval }^{\mathrm{b}}\end{array}$} & \multirow[t]{2}{*}{$\mathrm{R}^{2}$} & \multicolumn{2}{|c|}{ Gene effect } & \multirow{2}{*}{$\begin{array}{l}\text { Degree of } \\
\text { dominance }\end{array}$} & \multirow{2}{*}{$\begin{array}{l}\text { Gene } \\
\text { action }\end{array}$} \\
\hline & & & & & & & Additive & Dominant & & \\
\hline \multirow[t]{4}{*}{ Follicle size } & 1 & 14.01 & LF188:LF178 & 12.47 & $0-25.2$ & 6.7 & 6.89 & NA & NA & NA \\
\hline & 2 & 39.32 & AALUFO-84:AALUFO5-37 & 25.09 & $36.5-41.3$ & 8.9 & 4.75 & 4.46 & 0.94 & $\mathrm{D}$ \\
\hline & 2 & 67.87 & AALTM-69:AALLV-22 & 13.36 & $56.9-75.9$ & 5.3 & -4.99 & 7.33 & 1.46 & OD \\
\hline & 3 & 23.64 & AALLV-66:AALLV-121 & 21.46 & $20.2-32.0$ & 8.9 & 13.03 & -1.24 & 0.1 & A \\
\hline \multirow[t]{4}{*}{ Wing length } & 1 & 12.01 & LF188:LF178 & 13.05 & $0-20.0$ & 10 & -0.57 & NA & NA & NA \\
\hline & 2 & 24.83 & TrypB:AALTM-430 & 30.11 & $20.8-24.7$ & 6.8 & -0.74 & 2.7 & 3.67 & OD \\
\hline & 2 & 64.62 & AALF-80:AALTM-69 & 28.91 & $62.6-67.9$ & 7.2 & -1.04 & 2.87 & 2.74 & OD \\
\hline & 3 & 29.96 & AALLV-121:AALHD-44 & 119.39 & $23.6-33.5$ & 38.2 & 3.93 & 3.36 & 0.86 & $\mathrm{D}$ \\
\hline
\end{tabular}

Abbreviatios: a, additive; d, dominant; LR, likelihood ratio; NA, not applicable; QTL, quantitative trait loci.

${ }^{\text {a }}$ Chromosome position in cM.

${ }^{\mathrm{b}}$ Region flanking individual QTL peaks in which LOD scores decline by one LOD.

${ }^{c}$ Absolute value of dominance divided by additive (d/a) gene effect.

${ }^{\mathrm{d}}$ Mode of gene action determined as the absolute value of $\mathrm{d} / \mathrm{a}$ where additive $=0.0-0.20$, partial dominance $=0.21-0.80$, dominance $=$

0.81-1.20 and overdominance $=>1.20$ (after Stuber et al., 1987; Babu et al., 2006).

\section{Trait analysis}

We observed highly significant (Pearson correlation coefficient $=0.486 ; P<0.0001$ ) correlations between follicle size and wing length, suggesting strong genetic interrelationships between them. Comparisons of QTL positions across traits indicated that genes influencing autogeny and wing length reside, at a minimum, in the same chromosome regions (Figure 3). Comparisons of one-LOD support limit to define confidence intervals are consistent with a conclusion that the phenotypes are likely determined by groups of tightly linked genes, or possibly by some QTL with pleiotropic effects of single 

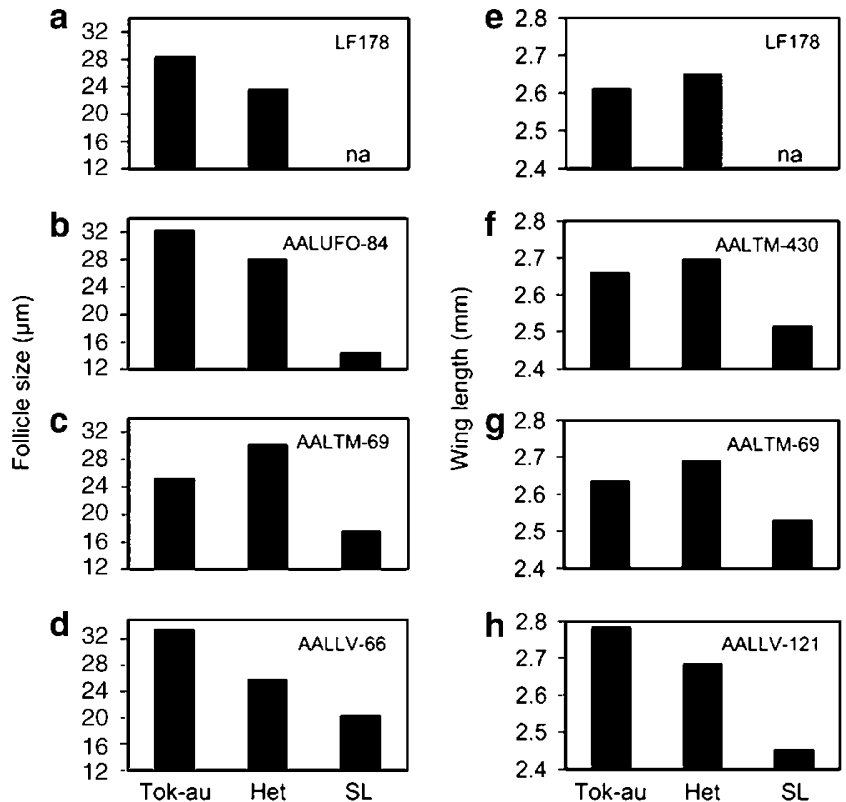

Figure 4 Mean phenotypes at 'best' marker locus for each QTL for (a-d) follicle size and (e-h) wing length. SL, Sri Lanka; Tok-au, autogenous strain. Histograms show means for Tok-au homozygotes, heterozygotes, SL homozygotes, respectively. NA, not applicable; for chromosome one loci, means are presented only for Tok-au homozygotes and heterozygotes due to autosomal sex determination (i.e., no male (SL parent) homozygote genotypes were recovered).

genes (Table 1). For instance, the 'best' marker for one of the chromosome 2 QTL in both of the traits was the AALTM-69 locus.

\section{Discussion}

Our QTL results confirm a multigenic mode of inheritance for autogeny in Ae. albopictus. We were able to rapidly select for a highly autogenous strain from stocks originally collected in Japan, and thereafter to identify QTL among $221 \mathrm{~F}_{1}$ intercross female progeny segregating for follicle size and wing length as a proxy for adult body size. The autogeny phenotype was evaluated as follicle size along their longitudinal axis. CIM analysis identified four QTL for follicle size, although a QTL on chromosome 1 is considered tentative $(P<0.1)$. Each QTL contributed a minor effect $(\leqslant 10 \%)$ to the phenotype and alleles from the autogenous parent showed dominance, overdominance or additive effects relative to the anautogenous parent.

CIM analysis also identified four QTL for wing length. Three QTL contributed a minor effect $(\leqslant 10 \%)$ to the phenotype, but a QTL on chromosome 3 had a major effect $(\sim 38 \%)$ on wing length. Alleles from the autogenous parent consistently showed dominance or overdominance effects on wing length relative to the anautogenous parent.

For most mosquitoes examined to date, including $A e$. albopictus, autogenous females are generally rare but clearly present among natural populations, although some species exhibit high frequencies in expression of the trait, including obligatory autogeny (Clements, 1992). Given that autogenous individuals have been identified across a broad range of mosquito species, it also seems most parsimonious that autogeny is a relict trait that predates the evolution of blood-feeding behavior.
Indeed, members of the mosquito subfamily Toxorhynchitinae, which do not blood feed acquire most of their nutrition for reproduction as larvae and many members of the family Chaoboridae, the ancestors of the mosquitoes, do not feed as adults.

Our QTL results for follicle size may support the hypothesis that autogeny is ancestral, as the observed inheritance patterns (dominance, overdominance and additivity) would facilitate maintenance of alleles for autogeny at low frequencies in populations. The rarity of autogeny has most often been ascribed to the negative fitness effects associated with reduced fecundity among autogenous females. Our comparison of fecundity among autogenous and anautogenous Ae. albopictus females support this conclusion as our Tok-au strain females produced $\sim 5.2$-fold more eggs following a blood meal (anautogeny) than through autogeny. Maintenance of alleles conferring autogeny in natural populations is likely due to balancing selection associated with several possible factors. Natural selection should increase the frequency of autogeny under conditions of limited host availability for blood feeding or increased defensive behavior by the host. The frequency of autogeny should also increase under optimum larval rearing conditions, because this will facilitate accumulation of sufficient nutrient reserves to support oogenesis by genetically autogenous females (Spielman, 1957; Trpis, 1978; Lounibos et al., 1982). Results from modeling studies indicated that host availability and nutrient larval conditions have the greatest influence on the frequency of autogeny (Tsuji et al., 1990). In further support of our results, Sota and Mogi (1994) observed that with Aedes togoi laboratory and natural populations in Japan, the frequency of autogeny was strongly correlated with optimal larval nutrition and larger adult body size. Another intriguing hypothesis to explain the 
maintenance of alleles for autogeny has been suggested for the blowfly, Lucilia cuprina; in that, selection for autogeny is indirect and actually the consequence of direct selection for adult starvation resistance (Cooper et al., 2002). That is, genetically autogenous individuals reared under adequate larval conditions gain a fitness advantage when the adults are subjected to limited nutrient resources, because of the increased stored nutrient carryover from larvae. This may apply to mosquitoes as well. For example, Ae. albopictus adult females from a colony selected for autogeny lived $\sim 1.3$ days longer, when maintained under starvation conditions than those from an anautogenous colony selected from the same genetic background (Chambers and Klowden, 1994).

Comparisons of QTL across traits suggest a nonrandom distribution in which we observed considerable overlap between each of the QTL for follicle size and wing length. In addition, we observed a highly significant correlation between these traits. Strong genetic and phenotypic correlations indicate that the two phenotypes are determined by up to four clusters of tightly linked genes or perhaps the pleiotropic effects of single genes. However, Tok-au females were only slightly larger than parent strain Tok females, indicating that our selection for autogeny did not concomitantly significantly influence body size. The frequency of autogeny has been shown to have a positive relationship with wing length in Ochlerotatus vigilax (Hugo et al., 2003), and increasing wing length has been positively correlated with fecundity among anautogenous Ae. albopictus and Aedes geniculatus females (Armbruster and Hutchinson, 2002), suggesting larger females carry greater nutrient reserves that can be directed toward egg development. Further, the association between body size and autogeny in $A$ e. togoi has been shown to vary geographically (Mogi et al., 1995); increased autogeny was associated with increased wing length among subarctic populations, but with decreased wing length among tropical populations. Clearly, additional research is needed to clarify the genetic relationship between autogeny and body size.

Mosquito genomics has achieved a level wherein the molecular genetic basis for complex traits such as autogeny and wing length can be elucidated. Complete annotated genome sequences are available for Aedes aegypti (Nene et al., 2007) and Anopheles gambiae (Holt et al., 2002), and will soon be available for Culex pipiens quinquefasciatus (http://cpipiens.vectorbase.org/ index.php). Because of its importance as a disease vector, it seems likely that the genome sequence for $A e$. albopictus will also be determined. These resources should facilitate comparative genomics approaches for identification of genes determining traits like autogeny or wing length that are common across mosquito species as well as potential species-specific genes.

\section{Acknowledgements}

We thank three anonymous reviewers for very helpful comments. This research was funded by grants AI33127, AI059342 and contract N01-AI25489 from the National Institute of Allergy and Infectious Diseases, National Institutes of Health, USA.

\section{References}

Armbruster P, Hutchinson RA (2002). Pupal mass and wing length as indicators of fecundity in Aedes albopictus and Aedes geniculatus (Diptera: Culicidae). J Med Entomol 39: 699-704.

Aslamkhan M, Laven H (1970). Inheritance of autogeny in the Culex pipiens complex. Pakistan J Zool 2: 121-147.

Attardo GM, Hansen IA, Raikhel AS (2005). Nutritional regulation of vitellogenesis in mosquitoes: implications for anautogeny. Insect Biochem Mol Biol 35: 661-675.

Babu R, Nair SK, Kumar A, Rao HS, Verma P, Gahalain A et al. (2006). Mapping QTL for popping ability in a popcorn $\times$ flint corn cross. Theor Appl Genet 112: 1392-1399.

Bassam BJ, Caetano-Anolles G, Gresshoff PM (1991). Fast and sensitive silver staining of DNA in polyacrylamide gels. Anal Biochem 196: 80-83.

Basten CJ, Weir BS, Zeng Z-B (2001). QTL Cartographer: A Reference Manual and Tutorial for QTL Mapping. Program in Statistical Genetics, Bioinformatics Research Center, Department of Statistics, North Carolina State University: Raleigh, NC.

Bat-Miriam M, Craig Jr GB (1966). Mutants in Aedes albopictus (Diptera: Culicidae). Mosq News 26: 13-22.

Black IV WC, DuTeau NM (1997). RAPD-PCR and SSCP analysis for insect population genetic studies. In: Crampton JM, Beard CB, Louis C (eds). The Molecular Biology of Insect Disease Vectors: A Methods Manual. Chapman \& Hall: London. pp 361-373..

Black IV WC, Kondratieff BC (2005). Evolution of arthropod disease vectors. in: Marquardt WC (ed). Biology of Disease Vectors, 2nd edn. Elsevier: Amsterdam. pp 9-23.

Bosio CF, Thomas RE, Grimstad PR, Rai KS (1992). Variation in the efficiency of vertical transmission of dengue- 1 virus by strains of Aedes albopictus (Dipera: Culicidae). J Med Entomol 29: 985-989.

Chambers EW, Lovin DD, Severson DW (2003). Utility of comparative anchor-tagged sequences as physical anchors for comparative genome analysis among the Culicidae. Am J Trop Med Hyg 69: 98-104.

Chambers GH, Klowden MJ (1994). Nutritional reserves of autogenous and anautogenous selected strains of Aedes albopictus (Diptera: Culicidae). J Med Entomol 31: 554-560.

Chambers GH, Klowden MJ (1996). Distention and sugar feeding induce autogenous egg development by the Asian tiger mosquito (Diptera: Culicidae). J Med Entomol 33: $372-378$.

Churchill GA, Doerge RW (1994). Empirical threshold values for quantitative trait mapping. Genetics 138: 963-971.

Clements AN (1963). The Physiology of Mosquitoes. Pergamon Press: Oxford.

Clements AN (1992). The Biology of Mosquitoes: Volume 1. Development, Nutrition and Reproduction. Chapman \& Hall: London.

Cooper K, Burd M, Lefevere KS (2002). Correlated response of autogeny to selection for adult starvation resistance in the blowfly, Lucilia cuprina. Heredity 88: 35-38.

Cui K-L (1982). The autogeny of Aedes albopictus in the Guangzhou area. Acta Entomol Sinica 25: 256-259.

Foster WA (1995). Mosquito sugar feeding and reproductive energetics. Ann Rev Entomol 40: 443-474.

Gubler DJ (2003). Aedes albopictus in Africa. Lancet Infect Dis 3: 751-752.

Gubler DJ, Rosen L (1976). Variation among geographic strains of Aedes albopictus in susceptibility to infection with dengue viruses. Amer J Trop Med Hyg 25: 318-325.

Hawley WA (1988). The biology of Aedes albopictus. I Amer Mosquito Control Assoc Suppl 4: 1-39.

Holt RA, Mani Subramanian G, Halpern A, Sutton GG, Charlab R, Nusskern DR et al. (2002). The genome sequence of the malaria mosquito Anopheles gambiae. Science 298: 129-149. 
Hoyer LC, Rozeboom LE (1976). Inheritance of autogeny in the Aedes scutellaris subgroup of mosquitoes. J Med Entomol 13: 193-197.

Hugo LE, Kay BH, Ryan PA (2003). Autogeny in Ochlerotatus vigilax (Diptera: Culicidae) from southeast Queensland, Australia. J Med Entomol 40: 897-902.

Lander ES, Green P, Abrahamson J, Barlow A, Daly M, Lincoln $S$ et al. (1987). MAPMAKER: an interactive computer package for constructing primary genetic linkage maps of experimental and natural populations. Genomics 1: 174-181.

Lounibos LP, Dover CV, O'Meara GF (1982). Fecundity, autogeny, and the larval environment of the pitcher-plant mosquito, Wyeomyia smithii. Oecologia 55: 160-164.

Medlock JM, Avenell D, Barrass I, Leach S (2006). Analysis of the potential for survival and seasonal activity of Aedes albopictus (Diptera: Culicidae) in the United Kingdom. I Vector Ecol 31: 292-304.

Mitchell CJ (1991). Vector competence of North and South American strains of Aedes albopictus for certain arboviruses: a review. J Amer Mosquito Control Assoc 7: 446-451.

Mogi M, Okazawa T, Sota T (1995). Geographical pattern in autogeny and wing length in Aedes togoi (Diptera: Culicidae). Mosquito Syst 27: 155-166.

Mori A (1979). Effects of larval density and nutrition on some attributes of immature and adult Aedes albopictus. Trop Med 21: 85-103.

Mutebi J-P, Black IV WC, Bosio CF, Sweeney Jr WP, Craig Jr GB (1997). Linkage map for the Asian tiger mosquito (Aedes (Stegomyia) albopictus) based on SSCP analysis of RAPD markers. Insect Mol Biol 88: 489-494

Nene V, Wortman JR, Lawson D, Haas B, Kodira C, Tu J et al. (2007). Genome sequence of Aedes aegypti, a major arbovirus vector. Science 316: 1718-1723.

O'Meara GF (1972). Polygenic regulation of fecundity in autogenous Aedes atropalpus. Entomol Exp Appl 15: 81-89.

Reiter P, Fontenille D, Paupy C (2006). Aedes albopictus as an epidemic vector of chikungunya virus: another emerging problem? Lancet 6: 463-464.

Severson DW (1997). RFLP analysis of insect genomes In: Crampton JM, Beard CB, Louis C (eds). The Molecular Biology of Insect Disease Vectors: A Methods Manual. Chapman \& Hall: London. pp 309-320.

Severson DW, Meece JK, Lovin DD, Saha G, Morlais I (2002). Linkage map organization of expressed sequence tags and sequence tagged sites in the mosquito, Aedes aegypti. Insect Mol Biol 11: 371-378.
Severson DW, Mori A, Kassner VA, Christensen BM (1995). Comparative linkage maps for the mosquitoes, Aedes albopictus and Aedes aegypti, based on common RFLP loci. Insect Mol Biol 4: 41-45.

Severson DW, Mori A, Zhang Y, Christensen BM (1993). Linkage map for Aedes aegypti using restriction fragment length polymorphisms. J Hered 84: 241-247.

Sota T, Mogi M (1994). Seasonal life cycle and autogeny in the mosquito Aedes togoi in northern Kyushu, Japan, with experimental analysis of the effects of temperature, photoperiod and food on life-history traits. Res Popul Ecol 36: 105-114.

Spielman A (1957). The inheritance of autogeny in the Culex pipiens complex of mosquitoes. Amer J Hyg 65: 404-425.

Spielman A (1971). Bionomics of autogenous mosquitoes. Ann Rev Entomol 16: 231-248.

Sprenger D, Wuithiranyagool T (1986). The discovery and distribution of Aedes albopictus in Harris County, Texas. J Amer Mosq Control Assoc 2: 217-219.

Stuber CW, Edwards MD, Wendel JF (1987). Molecular marker facilitated investigations of quantitative trait loci in maize. II. Factors influencing yield and its component traits. Crop Sci 27: 639-648.

Thomas V, Leng YP (1972). The inheritance of autogeny in Aedes (Finlaya) togoi (Theobald) from Malaysia and some aspects of its biology. Southeast Asian J Trop Pub Hlth 3: 163-174.

Trpis M (1978). Genetics of hematophagy and autogeny in the Aedes scutellaris complex (Diptera: Culicidae). J Med Entomol 15: $73-80$.

Tsuji N, Okazawa T, Yamamura N (1990). Autogenous and anautogenous mosquitoes: a mathematical analysis of reproductive strategies. I Med Entomol 27: 446-453.

Van Handel E, Day JF (1989). Correlation between wing length and protein content of mosquitoes. J Am Mosq Control Assoc 5: 180-182.

Yan G, Severson DW, Christensen BM (1997). Costs and benefits of mosquito refractoriness to malaria parasites: implications for genetic variability of mosquitoes and genetic control of malaria. Evolution 51: 441-450.

Zeng Z-B (1993). Theoretical basis for separation of multiple linked gene effects in mapping quantitative trait loci. Proc Natl Acad Sci USA 90: 10972-10976.

Zeng Z-B (1994). Precision mapping of quantitative trait loci. Genetics 136: 1457-1468.

Supplementary Information accompanies the paper on Heredity website (http://www.nature.com/hdy) 